\title{
Efetividade das audiências públicas como mecanismo de participação social: o caso da Agência Nacional de Saúde Suplementar
}

Effectiveness of public hearings as a social participation mechanism: the case of the National Supplementary Health Agency

\author{
Dominic Bigate Lourenço ${ }^{1}$ \\ Wilson Marques Vieira Junior ${ }^{2}$
}

\section{RESUMO}

Trata-se de artigo com o objetivo de avaliar a efetividade das audiências públicas realizadas pela Agência Nacional de Saúde Suplementar (ANS), enquanto mecanismos de participação social na formulação de políticas regulatórias do setor de saúde suplementar brasileiro. Considerando a importância das audiências públicas como mecanismos de participação social na formulação, implementação e controle de políticas públicas, revela-se necessário avaliar o grau de efetividade desses instrumentos. Nesse sentido, o presente artigo teve por finalidade identificar a representatividade dos atores que participam das audiências realizadas no âmbito da ANS, quais os temas debatidos e o grau de influência destes atores nas decisões do órgão regulador. A metodologia utilizada foi o estudo de caso, com uma abordagem qualitativa, a partir da análise de documentação indireta relativa às audiências realizadas. Os resultados encontrados apontam para a necessidade de aperfeiçoamento das audiências públicas, a fim de assegurar uma representatividade mais isonômica de todos os segmentos sociais impactados, garantindo, assim, maior efetividade ao instrumento.

Palavras-chave: audiência pública; participação social; ANS.

\begin{abstract}
This article aims to evaluate the effectiveness of public hearings of the National Agency of Supplementary Health (ANS) as mechanisms of social participation in the formulation of regulatory policies of the brazilian supplementary health sector. Considering the importance of public hearings as mechanisms of social participation in the formulation, implementation and control of public policies, it is necessary to evaluate the degree of effectiveness of these instruments. In this sense, this article aims to identify the representativeness of the actors who participate in the ANS hearings, the topics debated and the degree of influence of these actors in the decisions of the regulatory agency. The methodology used was the case study, with a qualitative approach, based on the analysis of indirect documentation related to the public hearings. The results point to the need for improvement of public hearings, in order to guarantee a more isonomic representation of all impacted social segments, thus ensuring greater effectiveness to the instrument.
\end{abstract}

Keywords: public hearing; social participation; ANS

\footnotetext{
${ }^{1}$ Mestranda em Políticas Públicas, Estratégias e Desenvolvimento do Instituto de Economia da Universidade Federal do Rio de Janeiro. Especialista em Regulação de Saúde Suplementar na Agência Nacional de Saúde Suplementar. E-mail: dominicbigate@gmail.com ${ }^{2}$ Mestre em Saúde Pública pela Escola Nacional de Saúde Pública; Especialista em Regulação de Saúde Suplementar na Agência Nacional de Saúde Suplementar. E-mail: wilsonmvir@yahoo.com
} 


\section{Introdução}

O artigo trata da efetividade das audiências públicas como mecanismos de participação social no processo de gestão de políticas regulatórias da Agência Nacional de Saúde Suplementar (ANS). De acordo com Soares (2002, p. 259), a audiência pública é uma das formas de participação e controle popular da Administração Pública no Estado Social e Democrático de Direito, propiciando à sociedade o intercâmbio de informações com a Administração Pública, o exercício da cidadania e o respeito ao princípio do devido processo legal em sentido substantivo. Importante destacar que as audiências públicas estão inseridas no conjunto de inovações institucionais da Constituição de 1988, tratando-se de promotoras da participação social nas relações entre Estado e sociedade (FONSECA et al, 2014).

Entretanto, a efetividade deste instrumento tem sido objeto de questionamento. Nesse sentido, Pires et al. (2011) alertam que a efetividade de processos participativos, dentre outros aspectos, depende do desenho institucional, das regras e normas estruturantes do processo, dos recursos disponibilizados e das relações de poder estabelecidas.

No âmbito da ANS, o Decreto no 3.327/2000, que aprovou o Regulamento da Agência, dispôs que o processo de edição de normas deste órgão regulador poderá ser precedido de audiência pública, sendo obrigatória, no caso de elaboração de anteprojeto de lei no âmbito da Agência. Vale destacar que a ANS é a agência reguladora criada para regular, controlar e fiscalizar os planos privados de assistência à saúde, que abarcam 47.188.528(quarenta e sete milhões, cento e oitenta e oito mil e quinhentos e vinte e oito) beneficiários, de acordo com dados da Agência de maio de 2019, o que revela a importância do setor no complexo econômico-industrial da saúde.

Portanto, considerando o impacto da saúde suplementar no sistema de saúde e até mesmo os aspectos econômicos do setor, a efetividade dos instrumentos de participação social utilizados no processo regulatório é importante a fim de garantir uma relação equilibrada e equânime entre Estado, mercado e sociedade, bem como garantir transparência e controle social às políticas públicas formuladas e implementadas.

O presente artigo está estruturado em uma introdução, na qual serão expostos os objetivos e a metodologia da pesquisa, seguindo-se da análise da participação social e sua relação com o Estado Democrático de Direito. A seguir serão apresentadas as principais características das audiências públicas e, por fim, será realizado o estudo de caso das audiências públicas realizadas pela ANS até 2018, a partir da análise dos Relatórios de Audiências Públicas (RAPs).

\subsection{Objetivos}

O objetivo geral do artigo é avaliar a efetividade das audiências públicas como mecanismo de participação social, com o recorte do caso da ANS. O artigo objetiva identificar quais atores têm participado das audiências públicas e que grupos sociais representam, a fim de analisar se há representatividade de todos os segmentos da sociedade atingidos pelas políticas regulatórias. Além disso, tem por finalidade identificar quais temas têm sido objeto desta modalidade de consulta à sociedade, a fim de verificar se, de fato, o instrumento tem sido utilizado para debater temas de relevante interesse social.

Por fim, o artigo tem por objetivo avaliar o grau de influência da participação destes atores, analisando o contexto da participação e os resultados alcançados perante o órgão regulador.

\subsection{Metodologia}

Tendo em vista a ampliação da participação social no país, experimentada a partir da Constituição Federal 
de 1988, com diferentes arranjos e contextos, torna-se importante a realização de estudos quanto à efetividade destes instrumentos. Assim, o presente trabalho tem por intuito realizar um estudo de caso sobre a efetividade das audiências públicas realizadas pela ANS, partindo da qualidade do processo em termos de representatividade.

Como acentuam Pires et al (2011), os aspectos qualitativos das instituições participativas têm estreita relação com a efetividade destes instrumentos, sendo relacionados, ademais, com os desenhos institucionais, com as regras disciplinadoras da ferramenta, com a atuação e recursos disponibilizados pela Administração Pública e pelas relações de poder envolvidas, dentre outros aspectos.

O presente trabalho, portanto, será centrado na análise qualitativa das audiências públicas realizadas pela ANS, por meio de dimensões que consideram aspectos concernentes à efetividade desta instituição participativa, tendo por base o modelo apresentado por Fonseca et al (2014, p. 12) em estudo sobre os fatores que influenciam o potencial de efetividade das audiências públicas.

Quadro 1 - Dimensões de análise do estudo

\section{Dimensões que caracterizam o processo}

- Atos normativos e seus impactos no processo

- Mapeamento dos principais atores e representatividade dos participantes

- Desenho e processo de realização das Audiências Públicas

- Transparência

Dimensões de resultado

- Impacto das contribuições na tomada de decisão

Fonte: Elaboração Própria com base em Fonseca et al (2014, p. 12)

A metodologia a ser empregada é a qualitativa, considerando que, segundo Minayo et al (2005, p. 81-82), essa modalidade de pesquisa tem foco na compreensão interpretativa da ação social, atuando de modo a considerar a compreensão e a inteligibilidade dos fenômenos sociais, o que é fundamental para a compreensão de instrumentos relacionados à forma como o Estado, o mercado e a sociedade se relacionam.

O tipo de pesquisa escolhido na abordagem qualitativa será a documental, realizada por meio de documentação indireta, qual seja, documentos disponibilizados pela ANS em seu sítio eletrônico, especialmente os Relatórios de Audiência Pública (RAPs), que condensam as principais informações sobre as audiências realizadas. Será também analisada a bibliografia sobre o tema, assim como a legislação relativa à matéria.

A metodologia foi escolhida considerando que dentre as vantagens da pesquisa documental está o fato de que, nesses documentos, as informações permanecem as mesmas após longos períodos de tempo, por terem origem em um determinado contexto histórico, econômico e social, fornecendo dados sobre esse contexto, independente do comportamento dos sujeitos (GODOY, 1995). 
Partindo da análise documental e da legislação sobre o tema, serão avaliadas as dimensões listadas no Quadro 1. Inicialmente, será analisada a legislação sobre a matéria e como esta interfere no instrumento. Considerando os dados apresentados pela ANS, serão verificados também os principais atores e os segmentos representados, a partir do número de participantes de cada segemento social e do número de contribuições formuladas por cada um deles. Também será prescrutado o desenho de realização das audiências, sendo considerado se este favorece o debate de ideias. Outro aspecto avaliado a partir das informações disponibilizadas é se a ANS atua de modo transparente em relação ao processo.

No que concerne à dimensão de resultado, para a avaliação do impacto das contribuições na tomada de decisão, serão verificadas as manifestações da ANS, apresentadas nos Relatórios de Audiência Pública, a respeito das contribuições formuladas, categorizando-as entre: acatadas; não acatadas; parcialmente acatadas; e não aplicáveis à matéria debatida.

Os dados obtidos a partir da análise documental e da legislação serão conjugados, a fim de verificar que segmentos da sociedade estão representados nas audiências públicas da ANS, qual a relação entre os temas objeto destas audiências e os instrumentos normativos editados no mesmo período e, por fim, qual o desfecho dado pela Agência às contribuições recebidas.

A partir da metodologia proposta objetiva-se identificar o desenho institucional das audiências públicas realizadas pela ANS, os principais atores e o impacto das contribuições recebidas, de modo a aferir a qualidade deste instrumento de participação social.

\section{Participação Social e democracia}

A presente seção abordará a participação social, a partir do conceito e da importância do instrumento no contexto do Estado Democrático de Direito, das principais características e da relação com a Constituição Federal de 1988.

O Estado Democrático de Direito tem como característica a participação direta, pela qual o particular pode influenciar na gestão e controle das decisões do Estado, como resultado do princípio democrático. Nesse sentido, instrumentos de participação, como as audiências públicas, são resultado da exigência da presença direta da sociedade civil na tomada de decisões como consequência da democracia representativa (SOARES, 2002).

Gordillo (1996, p. 454) considera que a participação dos administrados nos processos decisórios da Administração Pública é uma questão de sabedoria política, além de figurar como uma garantia objetiva de razoabilidade para o administrado quanto à percepção de que o Estado atua com apoio factual e proporcionalidade, assim como é um mecanismo de consenso da opinião pública a respeito do juridicidade e conveniência da ação estatal, funcionando, ademais, como uma garantia de transparência, democratização do poder e participação cidadã no poder público.

A esfera pública, segundo Tenório (2005, p. 107), é o espaço de comunicação e deliberação das relações envolvendo sociedade-Estado-mercado. Nesse sentido, para Gohn (2004, p. 29), a "ampliação da esfera pública contribui para a formação de consensos alcançados argumentativamente, numa gestão social compartilhada, gestada a partir de exercícios públicos deliberativos."

A participação na esfera pública se dá em um contexto de relações entre sociedade-Estado-mercado, de forma que as políticas públicas sejam fruto de uma concertação democrática dessas relações. No caso em análise, o contexto da participação ocorre justamente na formulação, implementação e controle de políticas públicas nas quais o Estado é representado pela ANS e o mercado representado pelas operadoras de planos privados de assistência à saúde. 
Jacobi (1989) destaca que o principal objetivo da participação é permitir o contato entre os cidadãos e as instituições públicas, interferindo nas concepções político-sociais do processo decisório, exercendo, ademais, maior controle sobre a coisa pública.

Para Da Silva et al (2005, p. 375), a participação amplia a transparência e a visibilidade das deliberações, democratizando o processo decisório, bem como confere maior expressão e visibilidade às demandas sociais, promovendo mais equidade e igualdade nas políticas públicas, sendo apta a promover a ampliação de direitos tendo em vista o interesse público, na medida em que permeia as ações do Estado em suas várias formas associativas.

De acordo com Tenório (2005), a participação contribui não apenas para a democracia, mas também para o fortalecimento da cidadania ativa. No mesmo sentido, Jacobi (1989) assevera que a descentralização é uma possibilidade de ampliação do exercício de direitos, participação e controle das políticas, dividindo o poder pelos variados segmentos sociais.

No Brasil, na Constituição de 1988, a participação social foi reconhecida como um elemento central na organização das políticas sociais nas áreas de saúde, educação, assistência social, previdência e trabalho, que dialoga com os princípios da democracia representativa e participativa, com vistas a assegurar a presença de variados atores sociais na formulação, gestão, implementação e controle de políticas sociais (DA SILVA et al, 2005).

É importante esclarecer, contudo, que a participação social pode ocorrer enquanto representação social junto às instâncias decisórias, como reafirmação do princípio de democracia participativa, mas também na execução de políticas públicas.

Enquanto reafirmação dos princípios da democracia participativa, a participação social é representada pela atuação de múltiplos atores nos processos de demanda, formulação, implementação e controle das políticas públicas, ou seja, é representada pela pluralidade de atores nos processos decisórios do Poder Executivo. A participação, prevista constitucionalmente como um canal de democracia participativa, foi institucionalizada por meio de conselhos e outras instâncias participativas (DA SILVA et al, 2005).

Por outo lado, a participação social também pode assumir a forma de execução de políticas públicas por atores da sociedade civil, como movimentos sociais e organizações não-governamentais (ONGs), sob uma ideia de protagonismo destes grupos em relação à atuação estatal (DA SILVA et al, 2005).

Vale destacar também, como acentuam Da Silva et al (2005), que há diversos pontos de vista sobre a atuação da sociedade civil, o tipo de Estado e as formas de participação social, das quais depende a abordagem dada ao tema.

Milani (2008, p. 556-557) aponta dois vieses da participação social. Um dos vieses é decorrente das políticas de downsizing, de reforma do Estado sob políticas de boa governança a partir dos anos 70 , no caso brasileiro a partir do final dos anos 90, como resultado da crise econômica. O argumento econômico é característico deste ponto de vista, segundo o qual a participação social figura como componente para uma prestação mais eficiente de bens públicos. O outro viés, não relacionado a uma ideia de reforma do Estado motivada por fatores externos, encara a participação social como um elemento da ressignificação do conceito de público, colocando as decisões em debate, com ênfase no aspecto político, em um contexto de reforma democrática do Estado e da Administração Pública.

A análise da participação social pode, ademais, ser compreendida em três níveis: como controle da qualidade dos serviços prestados; como definição das prioridades de bens públicos futuros; e como politização das relações sociais na construção de espaços públicos para a formulação de políticas públicas (MILANI, 2008, p. 559).

A participação social também pode ser exercida em diferentes graus de intensidade, variando entre um 
caráter meramente informativo, exercendo algum grau de influência sobre as decisões tomadas, atuando na elaboração da decisão ou até mesmo participando ativamente em um processo de co-decisão (MENCIO, 2007). Dessa forma, as participações podem distinguir-se quanto à obrigatoriedade ou não, quanto à vinculação da administração quanto ao resultado da participação e quanto ao prazo de antecedência em que será franqueada a participação (SILVA, 2009).

A respeito dos arranjos que envolvem a participação social, Avritzer $(2008$, p. 46) salienta que estes podem ser distinguidos por variáveis como: a iniciativa na proposição do desenho; o grau de organização da sociedade civil na área em questão; e a vontade política do governo em implementar a participação.

Uma outra questão que exsurge da temática da participação social é o quanto estes instrumentos têm impactos sobre as ações da Administração Pública, ou seja, o grau em que a participação influencia o processo decisório. Assim sendo, avaliar a qualidade dos processos participativos é uma questão de fundamental importância, a fim de compreender os impactos produzidos sobre as políticas públicas.

Almeida et al (2011, p.113) alertam que a avaliação quanto à efetividade das instituições participativas enfrenta questões complexas, como os fatores exógenos e anteriores ao processo, como a existência ou não de um associativismo local e o projeto político do governo. As autoras salientam, além disso, que além dos princípios deliberativos como referência, é necessário compreender quem institui e quem participa dos processos, as desigualdades no processo, a influência dos tipos de política, assim como o impacto de conflitos, auto interesse e argumentos estratégicos para a legitimidade democrática.

Nesse sentido, segundo Pires et al (2011, p.354), avaliar a qualidade do processo participativo por meio de variáveis explicativas permite ir além da mera avaliação quanto à existência ou não desses instrumentos nos processos decisórios, passando a considerar o "grau de presença" destas instituições, adentrando no grau de qualidade de funcionamento necessário à melhorias relacionadas às políticas públicas.

No Brasil, o processo de democratização deu azo a diversos arranjos institucionais para a ampliação da participação social, de maneira que a qualidade destes processos pode ser associada a várias dimensões, como os desenhos institucionais e o contexto em que exercem suas atividades (ALMEIDA et al, 2011).

Pires et al (2011) elencam, assim, cinco dimensões avaliativas quanto à qualidade da participação: inclusão e representatividade; desenho institucional; deliberação; contextos e ambiente institucional; e, por fim, atores e estratégias.

Silva (2011, p. 189-190) elenca, ademais, outras questões que devem ser levadas em conta em uma análise de uma instituição de participação social, como: a trajetória da política pública em questão; a permeabilidade da política pública quanto à participação social; as características institucionais do instrumento, como as capacidades técnicas e políticas da instituição; e as características dos atores envolvidos no processo, como as trajetórias, expectativas e "repertórios de ação".

Quanto aos desenhos institucionais, Avritzer (2008, p. 44), destaca três aspectos: a maneira como a participação se organiza; a forma como o Estado se relaciona com a participação; e como a legislação exige do governo a implementação ou não da participação.

No que concerne aos princípios norteadores das instituições participativas, Almeida et al (2011) sublinham a necessidade de que alguns princípios funcionem como pressupostos para a criação e funcionamento destes espaços, quais sejam: igualdade de participação; inclusão deliberativa; igualdade deliberativa; publicidade; reciprocidade/razoabilidade; liberdade; provisoriedade; conclusividade, não tirania; autonomia; e accountability. 3

3 Por igualdade de participação compreende-se a igualdade de oportunidade de participação no exercício deliberativo. Por inclusão deliberativa, denota-se a igualdade de avaliação das razões de todos os atores do processo. A igualdade deliberativa, por sua vez, corresponde à garantia de que todos possam apresentar suas razões em igualdade de condições. No que concerne à publicidade, este 
Considerar o grau de aderência aos princípios norteadores dos processos de participação social é importante para identificar como essas instituições se comportam nas realidades fáticas e como interferem nos resultados relacionados às políticas públicas. A ausência, por exemplo, de formas de garantia da igualdade de participação pode comprometer todo o processo participativo, levando a decisões enviesadas e que não tenham considerado todos os atores impactados pela política em discussão, distanciando-se dos princípios democráticos que inspiraram a construção destes instrumentos, comprometendo a própria razão de ser dos mesmos.

No Brasil, a Constituição Federal de 1988 trouxe uma série de inovações no sentido de institucionalizar processos de participação social, fazendo com que várias instituições participativas, em diferentes arranjos institucionais fossem criadas, gerando a necessidade de que a qualidade destes instrumentos seja avaliada, para que sua finalidade precípua seja atingida, resultando em melhorias na construção e implementação de políticas públicas.

\section{Audiências Públicas}

Nesta seção serão apresentadas as principais características das audiências públicas, a relação deste instrumento com a participação social e as previsões constitucionais sobre o tema.

As audiências públicas, no contexto das instituições de participação social, têm origem no princípio de justiça natural do direito anglo-saxão e no due process of law do direito americano, dotadas de natureza administrativa, representam uma garantia de devido processo no sentido substantivo, em que a coletividade é parte interessada e ativa. (GORDILLO, 1996).

As audiências públicas são uma das formas de participação e controle popular da Administração Pública no Estado Democrático de Direito, que visa ao exercício da cidadania e respeito ao devido processo legal em sentido substantivo, tendo como características a oralidade e o debate de matérias relevantes, conferindo legitimidade e transparência às decisões (SOARES, 2002).

Para Soares (2002, p. 261) as audiências públicas permitem que os diversos segmentos da sociedade que possam ser impactados por determinada decisão tenham a oportunidade de se manifestar em condições de igualdade, tratando-se de um "instrumento de conscientização comunitária".

Para Silva (2009, p. 74) a audiência pública não constitui um fim em si mesmo, pressupondo o exercício de uma competência discricionária, cuja realização depende de previsão legal ou da relevância social da questão, com regras previamente definidas e com ampla divulgação, cuja participação não é requisito para a validade da audiência, mas que é dotada de validade material, cuja decisão deve ser tomada em tempo oportuno para que não se afaste da realidade fática do momento em que foi realizada.

Dentre as vantagens da audiência pública estão o fato de que este instrumento pode evidenciar a intenção do administrador de produzir a melhor decisão, incentivar o consenso em torno da decisão adotada, demonstrar o cuidado com a transparência dos processos administrativos e aperfeiçoar o diálogo entre os agentes políticos e os eleitores (NETO, 1997).

No que concerne ao caráter vinculativo das audiências públicas, Soares (2002) assevera que estas não

princípio demanda que seja conferida a publicidade de todos os procedimentos e atos do processo. Pelo princípio da reciprocidade/razoabilidade determina-se que todos os participantes devem respeitar-se mutuamente e as razões expostas devem ser consideradas por todos, de forma recíproca. O princípio da liberdade, por sua vez, assegura as liberdades e garantias fundamentais de consciência, expressão, associação e manifestação. Pelo princípio da provisoriedade, as regras que regem a deliberação devem ser provisórias e podem ser contestadas. Além destes princípios, a conclusividade demanda a existência de uma decisão motivada, decorrentes das razões apresentadas no processo deliberativo, a não tirania implica em afastar influências como assimetrias de poder e desigualdades sociais, da autonomia decorre o exercício de opinar e manifestar preferências autodeterminadas pelos participantes e da accountability a possibilidade de revisão e análise dos argumentos expostos (ALMEIDA et al, 2011). 
vinculam a decisão da Administração Pública, tendo caráter consultivo, embora a autoridade administrativa deva analisar todas as contribuições, aceitando-as ou refutando-as de forma motivada.

Silva (2009), no mesmo sentido, considera que o resultado da audiência pública não é vinculante, porque sua finalidade é instrutória no âmbito do processo administrativo e de ampliação dos mecanismos de controle dos atos da Administração Pública, não retirando desta a competência da decisão.

Quanto aos requisitos para a realização das audiências públicas, segundo Soares (2002, p. 267) o principal requisito é a relevância da questão, traduzida como "interesse coletivo de reconhecida importância", ou seja, a questão deve transcender o interesse geral, devendo atingir a esfera de interesses de pessoas da coletividade, como nos casos que envolvem meio ambiente e direitos dos consumidores.

Os princípios que regem as audiências públicas, por sua vez, são: devido processo; publicidade; oralidade; informalismo; contraditório; participação; instrução; impulso de ofício; economia processual; e gratuidade (DAL BOSCO, 2002).

Já Neto (1997) elenca quinze princípios, acrescentando o princípio democrático, princípio da cidadania e da participação política, como pilares do reconhecimento de que o poder político emana do povo, ao qual devem ser submetidas as decisões sobre a coisa pública, seja por meio de representantes eleitos, seja por meio de mecanismos de participação direta. Neto (1997) também acrescenta os princípios da igualdade, da reserva legal, princípio associativo, da publicidade, do devido processo, do contraditório, da ampla defesa. Por fim elenca os princípios desenvolvidos pela tradição doutrinária do direito, quais sejam: da realidade; da lealdade; da motivação; da proporcionalidade; e da prevenção de litígios.

Na Constituição Federal de 1988 há diversas previsões quanto à realização de audiências públicas, vejamos: art. 29, XII - cooperação das associações representativas no planejamento municipal; art. 194, parágrafo único, VII - participação da comunidade nas decisões sobre a seguridade social; art. 198, III participação da comunidade nas ações e serviços públicos de saúde; art. 204, II - a participação da população através de organizações representativas na formulação de políticas de assistência social; art. 225, caput - implicitamente impõe à sociedade o dever de atuar para defender e preservar o meio ambiente; art. 58, parágrafo 2ํㅡ. II - adoção nominal pelas comissões do Congresso Nacional, nas matérias de sua competência, de audiências públicas com entidades da sociedade civil.

Fonseca et al (2014, p. 11) destacam que as principais características das audiências públicas são, em resumo, o caráter consultivo, pontual, presencial e coletivo do instrumento, assim como a manifestação oral dos participantes e o debate entre os atores envolvidos, além da abertura a todos os interessados e a necessidade de regras específicas para o seu funcionamento.

\section{Audiências Públicas na ANS}

Nesta seção as audiências públicas realizadas pela ANS até dezembro de 2018 serão analisadas, em uma perspectiva qualitativa, sob as seguintes dimensões de análise: os atos normativos que regulamentam o tema e os impactos no processo; os principais atores e a representatividade dos participantes; o desenho e o processo de realização das audiências públicas; a transparência das ações; e o impacto das contribuições apresentadas na tomada de decisão.

\subsection{Atos normativos e os impactos no processo}

A primeira dimensão de análise das audiências públicas realizadas pela ANS são os atos normativos que regulamentam a matéria e como estes atos influenciam o processo de organização e realização das audiências públicas. 
Como atentam Fonseca et al (2014), as previsões normativas podem servir à garantia da efetividade das audiências ou limitar o processo, ao engessá-lo.

No âmbito da ANS, o Decreto no 3.327/2000, que aprovou o Regulamento da Agência, nos artigos 32 e 33 , estabeleceu as diretrizes das audiências públicas.

A matéria levou dez anos para ser disciplinada internamente, por meio da Resolução Normativa nำ242, de 7 de dezembro de 2010, que trata da participação da sociedade civil e dos agentes regulados no processo de edição de normas e tomada de decisão da ANS. Vale destacar que a primeira audiência pública realizada pela ANS ocorreu apenas em janeiro de 2014.

O artigo $2^{\circ}$ da Resolução Normativa n 242 estabelece os objetivos das audiências públicas no âmbito da Agência, quais sejam: recolher sugestões e contribuições para o processo decisório da ANS e edição de atos normativos; propiciar à sociedade civil e aos agentes regulados a possibilidade de encaminhar sugestões e contribuições; identificar, da forma mais ampla possível, todos os aspectos relevantes à matéria submetida ao processo de participação democrática; dar maior legitimidade aos atos normativos e decisórios emitidos pela ANS; e dar publicidade à ação da ANS.

Como se vê, os objetivos elencados estão alinhados com os princípios democrático, da cidadania e da participação política, na medida em que permitem a participação da sociedade civil e dos agentes regulados no processo de formulação das políticas públicas relativas ao setor, em um processo de participação democrática.

No que tange ao caráter vinculativo das audiências, o artigo 3ำ prevê que as sugestões e contribuições recolhidas durante as audiências públicas são de caráter consultivo e não vinculante para a ANS.

Nos termos da Resolução Normativa ํำ 242, artigos 9ำ a 16, a convocação da audiência pública será formalizada por meio de publicação no Diário Oficial da União (DOU) e divulgada no sítio da ANS na internet, contendo a data e local da realização da audiência pública, a matéria objeto da audiência pública, o endereço eletrônico para requerimento dos interessados em participar da audiência pública e a indicação do link no sítio da ANS na internet onde será divulgada a audiência pública.

Os interessados deverão apresentar os pontos a defender, bem como indicar quem estão representando, quando for o caso. Cabe à ANS disponibilizar aos participantes material técnico, documentos ou estudos referentes à matéria objeto das audiências públicas, quando houver.

Após a realização de todas as etapas da audiência pública, a área técnica responsável pela condução do processo deverá divulgar no site da ANS um Relatório da Audiência Pública (RAP), que deverá conter a ata da audiência pública e seus respectivos anexos, a consolidação das principais sugestões e contribuições dos participantes, os dados estatísticos relativos à participação na audiência pública, a manifestação motivada sobre o acatamento ou a rejeição das principais sugestões e contribuições e a identificação das sugestões e contribuições incorporadas ao processo decisório.

O artigo 9, da Resolução Normativa no 242, estabelece que as audiências públicas serão realizadas por deliberação da Diretoria Colegiada da Agência, em matérias relevantes para o setor.

De acordo com o artigo 20 da supramencionada Resolução Normativa, o funcionamento das audiências públicas será definido em Regimento Interno específico elaborado e editado pela Diretoria da ANS competente para decidir sobre a matéria objeto de discussão. Sendo assim, cada audiência pública tem o seu respectivo Regimento Interno de funcionamento publicado.

Os atos normativos que regem a matéria franqueiam a participação nas audiências públicas a qualquer interessado, representando ou não interesses de grupos, não havendo critério de paridade quanto à representação de entidades, de modo que é possível que determinados segmentos sejam mais 
representados que os demais.

Além disso, não são previstos mecanismos de divulgação que atinjam todos os segmentos da sociedade, na medida em que a divulgação é restrita à publicação do Diário Oficial da União e divulgação no próprio sítio eletrônico da ANS, o que pode limitar a publicidade a grupos de interessados que acompanham a regulação setorial, afetando a representatividade de todos os setores eventualmente afetados.

Outro ponto que merece destaque é que a regulamentação do tema não prevê de modo claro quais seriam as matérias relevantes e nem eventuais critérios de relevância ensejadores da realização das audiências, deixando uma margem decisória subjetiva à Diretoria Colegiada da Agência, o que pode fazer com que o instrumento seja utilizado de forma casuística, eivando seu caráter democrático-participativo.

Desse modo, o que se verifica é que os atos normativos que regulamentam a matéria dão ampla margem aos gestores na organização das audiências, o que, por um lado, é importante a fim de garantir que o instrumento possa ser utilizado de maneira mais adequada a cada caso concreto, mas, por outro lado, dá margem a vieses, como no caso da ausência de critérios mais claros quanto à relevância social da questão, o que pode afetar a efetividade do instrumento na conformação das políticas públicas do setor.

\subsection{Mapeamento dos principais atores e representatividade dos participantes}

Inicialmente, cumpre elencar os principais atores do processo de participação social em análise, dentre os quais estão: a) ANS; b) representantes do mercado regulado; c) órgãos de defesa do consumidor; c) servidores públicos da ANS; d) representantes dos prestadores de serviços de assistência à saúde; e e) empresas que prestam serviços de consultoria; dentre outros.

Ao analisar a representatividade dos participantes, verificamos uma participação expressiva do mercado regulado, seguida dos prestadores de serviços e baixa representatividade dos consumidores 4 :

Tabela 1 - Participação por entidade

Entidades Participantes

№ de Participantes

Entidades representativas e profissionais das operadoras de planos privados de assistência à saúde

Entidades

representativas

e

profissionais

dos prestadores de serviços de assistência à saúde

Consultorias 
Órgãos Públicos Externos à ANS

Imprensa

Fundos de Investimento

Representantes de Instituições de Ensino Superior e Pesquisa

Representantes da Indústria Química, Farmacêutica e Biotecnológica

Cidadãos

$\mathrm{OAB}$
Total Geral

Fonte: Elaboração Própria

A baixa representatividade dos consumidores indica um déficit que é destacado quando se verifica as contribuições recebidas nas audiências. As contribuições provenientes dos órgãos de defesa do consumidor representam apenas $3 \%$ do total:

Tabela 2 - Contribuições por entidade

\section{Entidades}

\section{№ de Contribuições}

Entidades representativas e profissionais das operadoras de planos privados de assistência à saúde

Entidades representativas e profissionais dos prestadores de serviços de assistência à saúde

Consultorias

Representantes de outras categorias 
Cidadãos

$\mathrm{OAB}$

Imprensa
2

1

0

0

0

Fonte: Elaboração Própria

Se considerarmos apenas as audiências relativas a temas que afetam diretamente os consumidores, o número de contribuições das entidades de defesa do consumidor corresponde a $13 \%$. Vale destacar, entretanto, que ao longo dos anos tem sido observado um aumento, passando de 1(uma) contribuição em 2016, para 8 (oito) em 2018.

Outro ponto que merece atenção é a baixa participação de indivíduos que não tenham vínculo de representatividade com alguma entidade. Foram registradas 11 (onze) participações e 2 (duas) contribuições provenientes de cidadãos, o que demonstra que a participação, em geral, não ocorre diretamente, mas por meio de representantes de atores como o mercado regulado, prestadores de serviços e órgãos de defesa do consumidor.

Portanto, como é possível depreender da análise realizada, embora as audiências públicas realizadas pela ANS sejam abertas à participação de toda a sociedade, observa-se que a participação efetiva é preponderantemente do mercado regulado, o que pode mitigar os efeitos das audiências enquanto mecanismos de equacionamento de demandas de todos os setores afetados pelas políticas públicas em debate.

\subsection{Desenho e processo de realização das Audiências Públicas}

As audiências públicas na ANS são regidas por um regimento interno, publicado a cada audiência, que regulamenta o processo de realização, participação e divulgação dos resultados.

Como destacam Fonseca et al (2014) também é importante identificar o momento do ciclo da política pública em que as audiências ocorrem. Para os autores, as audiências públicas devem ocorrer em um momento em que ainda seja possível agregar demandas na temática debatida.

No caso da ANS, a maior parte das audiências públicas ocorreu quando já havia uma minuta de ato normativo preparado pelo órgão regulador, tratando-se de uma fase em que a questão em discussão já é apresentada a partir do ponto de vista da Administração Pública, em que pese haja a possibilidade de incorporar questões à matéria.

No que diz respeito ao rito, ao analisar os regimentos internos das audiências públicas realizadas pela ANS até 2018, verifica-se que estas demandam uma inscrição prévia dos participantes, no qual estes devem indicar se são representantes de alguma entidade, caso o sejam, e os pontos que serão abordados. Além 
disso, os regimentos disciplinam, de um modo geral, um rito que engloba a abertura do evento, a apresentação do assunto pela Agência e a participação dos interessados.

O rito de participação é descrito nos regimentos internos, prevendo a duração de 3 (três) minutos para as manifestações, garantindo, ademais, a possibilidade de réplicas e tréplicas de até 1 (um) minuto. $O$ rito de realização da audiência pública na ANS, portanto, garante a manifestação e a discussão dos temas entre o órgão regulador e os participantes, nas figuras da réplica e tréplica. Vale destacar que nos regimentos internos da $2^{\underline{a}}$ e da $6^{\underline{a}}$ audiências o rito acima descrito não foi previsto.

A $10^{\mathrm{a}}, 11^{\mathrm{a}}$ e $13^{\mathrm{a}}$ audiências públicas trouxeram, ademais, em seus regimentos internos, a possibilidade de que os participantes também realizassem apresentações, nos seguintes termos: "As apresentações terão prazo máximo de 10 (dez) minutos, sendo abertos 5 (cinco) minutos para perguntas, limitados a 1 (um) minuto por pergunta, sobre a exposição realizada;"

Além disso, nos regimentos internos das $10^{\underline{a}}, 11^{\underline{a}}$ e $13^{a}$ audiências constou a determinação de reserva de assentos para a imprensa e a previsão de que entidades representativas de caráter nacional teriam prioridade em relação a entidades representativas de caráter regional.

No que concerne a privilegiar a participação de entidades de caráter nacional em detrimento de entidades de caráter regional, um dos possíveis efeitos é desconsiderar questões regionais nas decisões, aplicando regras gerais que não se adequem a realidades locais.

Como é possível verificar, o rito, de um modo geral, prevê o debate de ideias entre os participantes, com escopo delimitado, mediado pelo órgão regulador. Em alguns casos houve, inclusive, a possibilidade de que participantes realizassem apresentações, além da possibilidade de manifestação oral.

O rito possibilita a sistematização das contribuições pelo órgão regulador, entretanto, é importante ressaltar que a mediação realizada pela ANS tem caráter muito técnico, assim como o próprio escopo das audiências, o que dificulta a participação de determinados segmentos da sociedade, em virtude da grande assimetria de informação do setor.

No que concerne ao processo de realização das audiências públicas também é importante repisar que o instrumento foi regulamentado apenas em 2010 e efetivado em 2014, sendo realizadas 13 (treze) audiências até dezembro de 2018. A série histórica demonstra, ademais, que o número de audiências públicas realizadas pela ANS se intensificou em 2018:

Gráfico 1 - Evolução no no de Audiências Públicas realizadas pela ANS

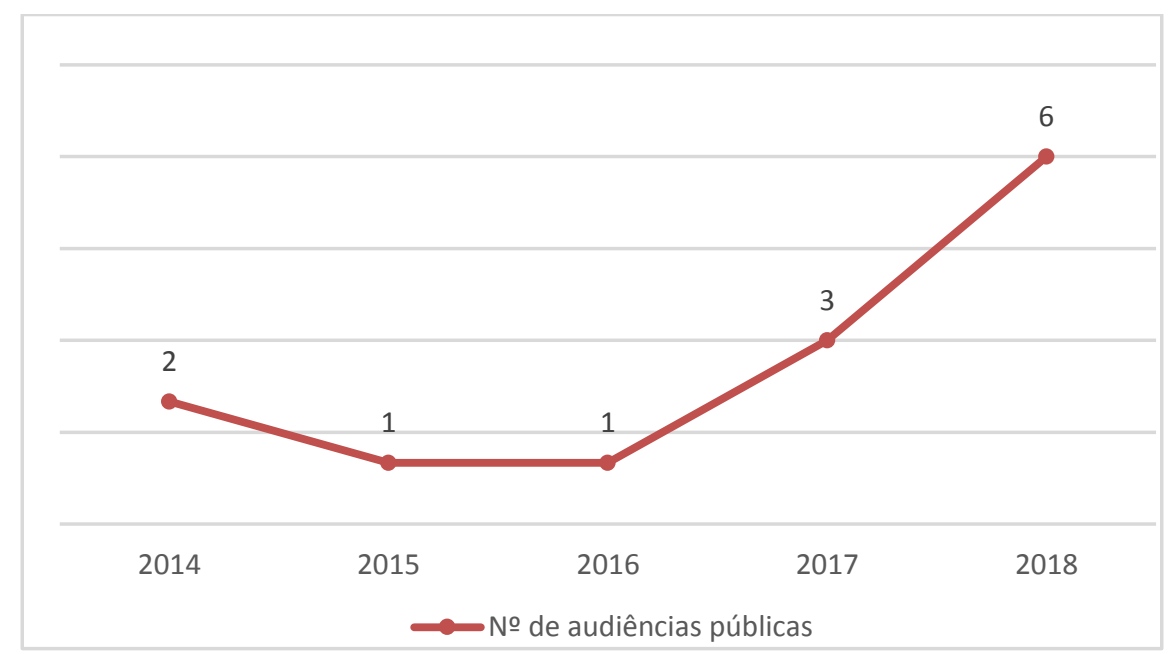

Fonte: Elaboração Própria 
Importante lembrar que, conforme Gordillo (1996, p. 458), para a Administração Pública é interessante realizar o maior número de audiências públicas possível, para a obtenção de maior consenso na opinião pública, apoio à legitimidade da sociedade, eficácia das decisões e consolidação da imagem da própria Administração perante a opinião pública no cumprimento de suas funções.

Portanto, o que se verifica é uma ampliação quanto à utilização do instrumento de 2014 a 2018, em que pese a demora para a implementação. Ao comparar o número de audiências públicas realizadas com o número de Resoluções Normativas editadas no mesmo período, é possível observar que o número de resoluções diminui ao longo do tempo, enquanto o número de audiências aumenta, o que demonstra a ampliação proporcional na utilização da ferramenta:

Gráfico 2 - Comparação entre o ํo de Audiências Públicas e o no de Resoluções Normativas

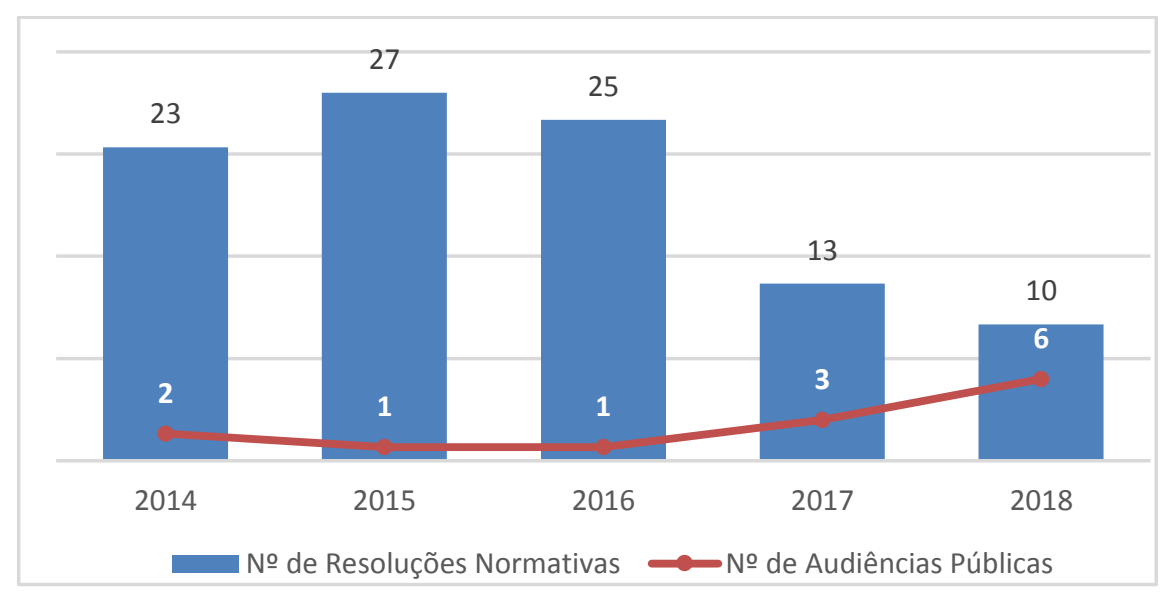

Fonte: Elaboração Própria

Fonseca et al (2014) também assinalam que o recorte do objeto da audiência é fundamental para a efetividade das audiências, na medida em que os interessados devem ter a possibilidade de opinar sobre os assuntos que considerem importantes, assim como para facilitar o tratamento que será dado às contribuições recebidas. Assim, no que concerne ao eixo temático, é possível verificar uma grande concentração de audiências públicas relacionadas à regulamentação de aspectos econômico-financeiros das operadoras, vejamos:

Gráfico 3 - Distribuição temática das audiências públicas realizadas pela ANS

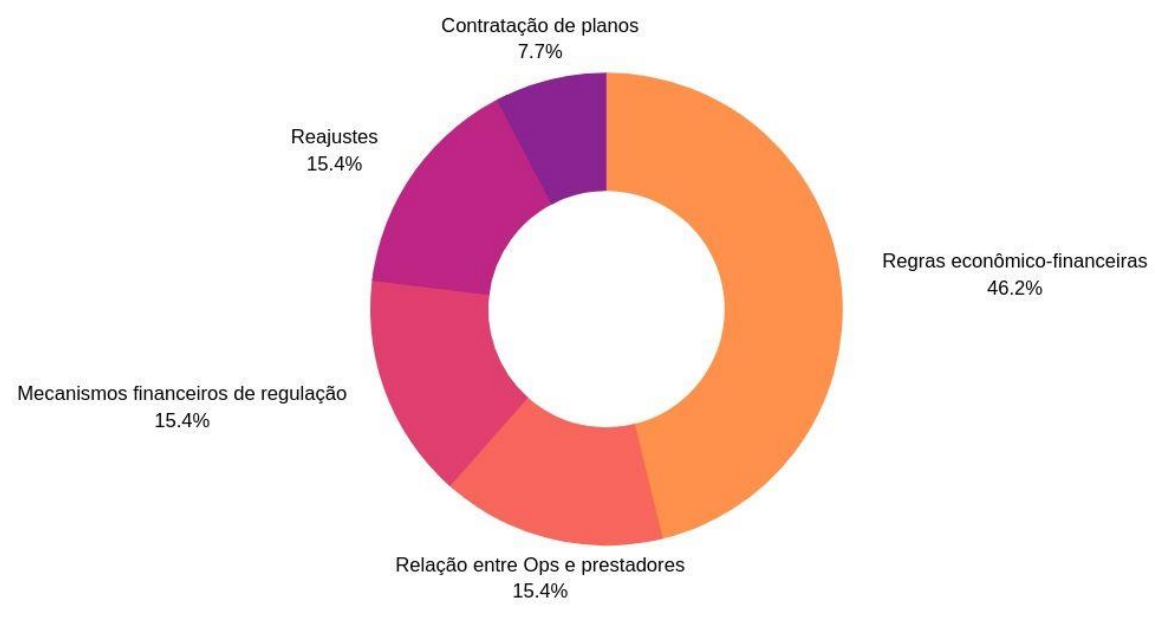

Fonte: Elaboração Própria 
No que se refere aos assuntos debatidos em sede de audiências públicas, como já observado, verifica-se que não há um critério claro quanto à relevância social dos temas debatidos, centrando-se, de modo prioritário, em matérias relacionadas ao mercado regulado, uma vez que apenas $38 \%$ das audiências eram referentes a matérias que impactam diretamente beneficiários - reajustes, contratação de planos e mecanismos financeiros de regulação.

Ao comparar os temas debatidos nas audiências públicas realizadas com os temas das Resoluções Normativas do período em análise, verifica-se que $19 \%$ dos atos normativos publicados no período são relacionados à regulamentação de aspectos econômico-financeiros, $8 \%$ relacionados à regulamentação da relação entre operadoras e prestadores, $5 \%$ relativos à regulamentação quanto à contratação de planos, $4 \%$ sobre reajustes e $2 \%$ sobre mecanismos financeiros de regulação:

Tabela 3 - Resoluções Normativas publicadas entre 2014-2018 por assunto

\begin{tabular}{|c|c|}
\hline Resoluções Normativas editadas entre $2014-2018$ por assunto & Total: \\
\hline Regulamentação econômico-financeira das operadoras & 18 \\
\hline Regulamentação sobre o Regimento Interno da ANS & 16 \\
\hline Regulamentação sobre regras de autorização e funcionamento & 14 \\
\hline Regulamentação sobre cobertura & 11 \\
\hline Regulamentação da relação entre operadoras e prestadores & 8 \\
\hline Regulamentação sobre temas variados & 7 \\
\hline Regulamentação sobre processo de fiscalização & 6 \\
\hline Regulamentação sobre contratação de planos & 5 \\
\hline Regulamentação dos reajustes & 4 \\
\hline Regulamentação sobre Ressarcimento ao SUS & 3 \\
\hline Regulamentação da Câmara de Saúde Suplementar & 3 \\
\hline $\begin{array}{l}\text { Regulamentação sobre mecanismos financeiros de regulação } \\
\text { (coparticipação e franquia) }\end{array}$ & 2 \\
\hline Regulamentação da portabilidade & 1 \\
\hline Total Geral: & 98 \\
\hline
\end{tabular}

Fonte: Elaboração Própria. 
Portanto, verifica-se uma relação de proporcionalidade entre os atos normativos editados no período e os temas debatidos em sede de audiência pública.

Assim, no que se refere ao escopo das audiências públicas realizadas, é possível verificar que estes tendem a ser bem delimitados e guardar uma relação de proporcionalidade com os atos normativos editados, contudo, deve ser repisado que não há critérios claros de identificação de temas de relevância social.

\subsection{Impacto das contribuições na tomada de decisão}

Todas as informações relacionadas às audiências públicas realizadas no âmbito da ANS são consolidadas no Relatório de Audiência Pública (RAP), no qual constam os dados estatísticos quanto à participação e contribuições recebidas. Esses relatórios, a despeito de serem estruturados de modo similar, não são padronizados, variando de uma audiência para outra.

Vale destacar que os relatórios da $1^{\underline{a}}$ e da $6^{\underline{a}}$ audiências públicas não enfrentaram a análise das contribuições recebidas, de modo que não foi possível utilizá-las a fim de aferir a qualidade do processo.

Apenas no relatório da $7^{\underline{a}}$ audiência pública constou uma classificação da ANS quanto ao acatamento ou não das contribuições recebidas. Nos demais casos, embora haja manifestação quanto ao teor das contribuições, não foi realizada uma categorização quanto ao desfecho das contribuições recebidas.

No presente estudo, as contribuições foram categorizadas quanto ao desfecho, a partir da análise das manifestações da ANS. Em relação à $7^{a}$ audiência pública, foram consideradas as classificações formuladas pelo próprio órgão regulador. Assim, as contribuições recebidas foram classificadas em: a) acatadas, quando integralmente incorporadas; b) não acatadas, quando foram rechaçadas de plano pela ANS; c) parcialmente acatadas, quando não foram incorporadas na íntegra ou quando foram consideradas para fins de discussão atual ou futura, embora não tenham sido incorporadas de imediato; e d) não se aplica, quando as contribuições não guardavam pertinência com o tema debatido.

Desse modo, ao categorizar as manifestações da ANS a respeito das contribuições recebidas nas audiências públicas, foi possível verificar que apenas $10 \%$ foram integralmente acatadas, vejamos:

Gráfico 4 - Análise das contribuições recebidas

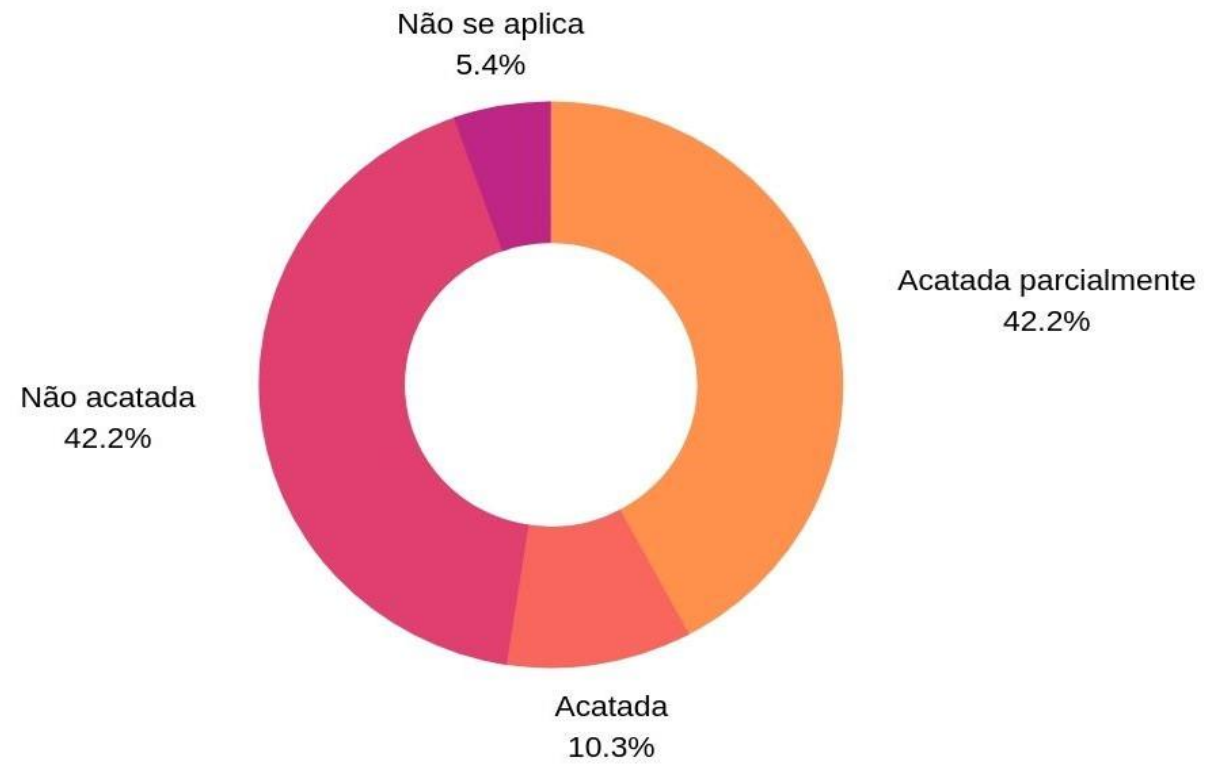

Fonte: Elaboração Própria 
Também é possível observar que $42,2 \%$ das contribuições foram acatadas parcialmente, ou seja, a despeito de não terem sido incorporadas integralmente, foram consideradas no processo decisório.

Ao analisar as contribuições por grupos de contribuintes, é possível verificar que nenhuma contribuição de entidades de defesa do consumidor foi acatada integralmente e que as empresas que prestam consultorias no setor tiveram o maior percentual de contribuições acatadas. Já as operadoras de planos de saúde e prestadores seguiram um padrão similar:

Gráfico 5 - Desfecho das contribuições por segmento social

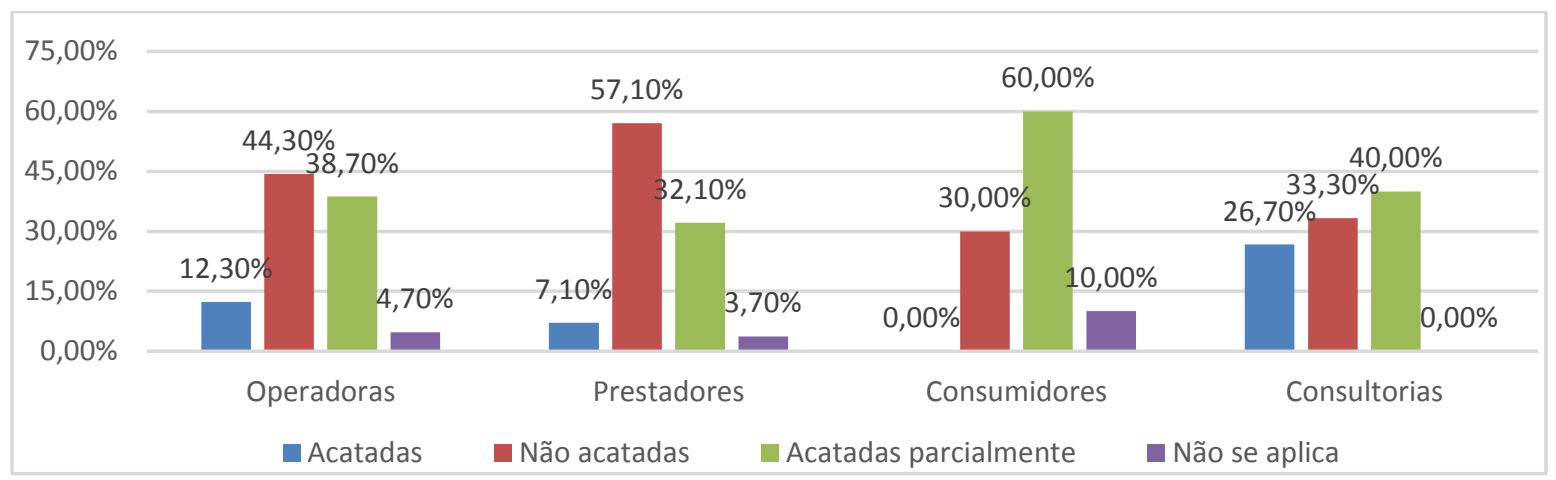

Fonte: Elaboração Própria

Ao considerar a análise da ANS sobre as contribuições recebidas durante as audiências públicas, é possível observar que grande parte é acatada apenas parcialmente, muitas vezes sendo consideradas apenas para fins de incorporação às próximas discussões, sendo de difícil aferição identificar os desdobramentos futuros.

Nesse sentido, é possível concluir que a Agência acata um percentual reduzido das contribuições apresentadas e que, na maior parte dos casos, incorpora apenas parcialmente as contribuições ou declara que as utilizará para fins de formulação futura das políticas públicas discutidas.

Outro ponto que merece destaque é relativo à distribuição das contribuições entre os participantes, já que a participação do mercado regulado é muito superior à participação de outros segmentos da sociedade. Dessa forma, ao analisar as contribuições incorporadas ao processo decisório pela Agência, é fundamental coadunar essas informações com a proporcionalidade do grupo representado.

Sendo assim, verifica-se que a participação dos órgãos de defesa do consumidor, cidadãos que não tenham vínculos de representatividade, meio acadêmico, dentre outros segmentos, têm uma participação muito pequena em termos de contribuição e incorporação de ideias no debate sobre as políticas públicas de saúde suplementar, o que precisa ser enfrentado a fim de garantir maior isonomia em termos de participação social.

\subsection{Transparência}

No que se refere à transparência, foi constatado durante a pesquisa que a ANS disponibiliza todos os documentos relativos às audiências públicas realizadas em seu endereço eletrônico, garantindo o livre acesso aos cidadãos.

Foi verificado, ademais, que são disponibilizados documentos técnicos da Agência sobre os temas debatidos e, em alguns casos, gravações das audiências. Estes documentos são redigidos em linguagem 
técnica, o que pode dificultar a compreensão de alguns segmentos da sociedade.

No que se refere à divulgação quanto à realização das audiências, como já exposto, não há mecanismos que garantam a divulgação em locais de amplo acesso, como jornais de grande circulação, o que pode enviesar a participação, na medida em que apenas atores familiarizados com o acesso rotineiro ao sítio eletrônico da Agência podem ter conhecimento quanto à data e horário de realização.

\section{Considerações Finais}

Dentre os achados da pesquisa observou-se uma demora na implementação do instrumento pela ANS, com resultados que indicam grande assimetria de participação entre os diversos atores do setor, com forte preponderância do mercado regulado e diminuta participação dos consumidores, o que revela que as audiências públicas ainda carecem de mecanismos que garantam a efetiva participação social de todos os segmentos da sociedade afetados pelas políticas públicas em análise.

É possível verificar, ademais, que um baixo percentual de contribuições é incorporado pela ANS no processo decisório, embora a Agência demonstre a intenção de utilizar parte das contribuições não incorporadas em discussões futuras sobre o tema.

Ainda que a ANS preveja a ampla participação da sociedade e transparência das ações relacionadas às audiências públicas, é necessário enfrentar a assimetria de informação que compromete a participação de consumidores e cidadãos e outros segmentos afetados pelos assuntos debatidos, sob pena de enviesar estes mecanismos, transformando-os em um ambiente de debate restrito aos agentes do mercado regulado e ao órgão regulador.

Portanto, embora a Agência tenha ampliado a utilização das audiências públicas como instrumento de participação social nos últimos anos, é importante aprimorar o instrumento, de modo a garantir a qualidade e a efetividade deste na formulação, implementação e controle das políticas regulatórias de saúde suplementar.

Por fim, é importante salientar que o presente trabalho se restringiu à análise das audiências públicas, a partir dos documentos disponibilizados no sítio eletrônico da ANS. Contudo, como asseveram Fonseca et al (2014),o uso das audiências públicas é pontual e algumas políticas públicas demandam outros instrumentos participativos, de forma que para melhor compreender a participação social no âmbito da ANS é necessário avaliar também os demais instrumentos de participação social utilizados e outros aspectos da participação, como a percepção dos participantes sobre o processo, uma avaliação pormenorizada dos próprios participantes e os desdobramentos futuros dos temas debatidos.

\section{Referências}

ALMEIDA, Debora C. Rezende et al. A análise da deliberação democrática: princípios, conceitos e variáveis relevantes. Efetividade das instituições participativas no Brasil: estratégias de avaliação. Brasília, DF: Ipea, p. 109-123, 2011.

ANS - AUDIÊNCIAS PÚBLICAS. Disponível em: < http://www.ans.gov.br/participacao-dasociedade/audiencias-publicas>. Acesso em 05 de mai de 2019.

AVRITZER, Leonardo. Instituições participativas e desenho institucional: algumas considerações sobre a variação da participação no Brasil democrático. Opinião pública, v. 14, n. 1, p. 43-64, 2008. 
BRASIL. Constituição Federal. Constituição da República Federativa do Brasil de 1988. Disponível em http://www.planalto.gov.br/ccivil 03/constituicao/constituicaocompilado.htm. Acesso em 15 de mai de 2019.

BRASIL. Decreto nํ⒊327, de 05 de janeiro de 2000. Aprova o Regulamento da Agência Nacional de Saúde Suplementar - ANS, e dá outras providências. Disponível em: <http://www.planalto.gov.br/ccivil_03/decreto/D3327.htm>. Acesso em 15 de mai 2019.

BRASIL. Resolução Normativa nำ242, de 7 de dezembro de 2010. Dispõe sobre a participação da sociedade civil e dos agentes regulados no processo de edição de normas e tomada de decisão da Agência Nacional de Saúde Suplementar - $\quad$ ANS. Disponível em: $<$ http://www.ans.gov.br/component/legislacao/?view=legislacao\&task=TextoLei\&format=raw\&id=MTYxNg= $=>$. Acesso em 15 de mai 2019 .

DA SILVA, Frederico Barbosa; JACCOUD, Luciana; BEGHIN, Nathalie. Políticas sociais no Brasil: participação social, conselhos e parcerias. Questão Social e Políticas Sociais no Brasil Contemporâneo. Brasília: Ipea, 2005.

DAL BOSCO, Maria Goretti. Audiência pública como direito de participação. Revista dos Tribunais, p. 727739, 2002.

DE SOUZA MINAYO, Maria Cecília; DE ASSIS, Simone Gonçalves; DE SOUZA, Edinilsa Ramos. Avaliação por triangulação de métodos: abordagem de programas sociais. [s.I.]: SciELO-Editora FIOCRUZ, 2005.

FONSECA, Igor Ferraz et al. Audiências públicas: fatores que influenciam seu potencial de efetividade no âmbito do Poder Executivo federal. Revista do Serviço Público, v. 64, n. 1, p. 7-29, 2014.

GODOY, Arilda Schmidt. Pesquisa qualitativa: tipos fundamentais. Revista de Administração de empresas, v. 35, n. 3, p. 20-29, 1995.

GOHN, Maria da Glória. Empoderamento e participação da comunidade em políticas sociais. Saúde e sociedade, v. 13, p. 20-31, 2004.

GORDILLO, Agustín. Procedimiento de Audiencia Pública. RAP. Julio, 1996.

JACOBI, Pedro. Políticas Públicas. São Paulo, Cortez, 1989.

MENCIO, Mariana et al. O regime jurídico da audiência pública na gestão democrática das cidades. 2007. 
MILANI, Carlos Roberto Sanchez. O princípio da participação social na gestão de políticas públicas locais: uma análise de experiências latino-americanas e europeias. 2008.

NETO, Diogo de Figueiredo Moreira. Audiências públicas. Revista de Direito Administrativo, v. 210, p. 11 23, 1997.

PIRES, Roberto Rocha C. et al. Em busca de uma síntese: ambições comuns e abordagens diversificadas na avaliação da efetividade das instituições participativas. Efetividade das instituições participativas no Brasil: estratégias de avaliação. Brasília: Ipea, p. 347-364, 2011.

SILVA, Alessandra Obara Soares da et al. Participação popular na administração pública: as audiências públicas. 2009.

SILVA, Fabio de Sá. De cada um conforme suas capacidades: participação, ambientes institucionais e capacidade de incidência em políticas públicas. 2011.

SOARES, Evanna. Audiência pública no processo administrativo. Revista de direito administrativo, v. 229, p. 259-284, 2002.

TENÓRIO, Fernando Guilherme. (Re) visitando o conceito de gestão social. Desenvolvimento em questão, v. 3, n. 5, p. 101-124, 2005. 